\title{
Urinary infection and malformations of urinary tract in infancy
}

\author{
E RING AND G ZOBEL \\ Department of Paediatrics, University of Graz, Austria
}

SUMMARY One hundred and forty infants with their first urinary tract infections were studied and pronounced differences in age and sex were found. Two thirds of the patients had their first urinary tract infection during the first three months of life, and boys were significantly younger. There was a predominance of boys from 1-3 months old, but of girls thereafter. Obstructive uropathies occurred more often in boys, and during the first two months of life. The incidence of vesicoureteric reflux was similar for both sexes. Malformations recognised after urinary tract infections were compared with urinary tract malformations recognised prenatally. Fetal urinary tracts were evaluated in just over half of all pregnancies during the study period. Obstructive uropathies and multicystic dysplastic kidneys were more often diagnosed prenatally, and most refluxes were diagnosed after the urinary tract infection.

In conclusion age and sex differences are common in urinary tract infection, and even though many urinary tract malformations were diagnosed prenatally this did not influence the high incidence of malformations recognised after urinary tract infection in infancy.

Urinary tract infection is one of the most common bacterial infections in infancy and childhood. Previous studies have reported age and sex related differences in urinary tract infection and urinary tract malformations. ${ }^{1-5}$ Though the importance of urinary tract infection during the first year of life is well known, only a few studies concern this particular period. . $^{-9}$

During recent years ultrasonography has improved the diagnosis of urinary tract malformations and enabled us to diagnose them prenatally. We report the data of 140 infants all of whom had what was thought to be their first urinary tract infection and also those of 39 infants with urinary tract malformations diagnosed prenatally during the study period. The first aim of the study was to look for age and sex related differences in urinary tract infection in infancy, and to find out whether these differences are common features or whether they change with time. The second aim was to compare the types of urinary tract malformation detected after urinary tract infection in infancy with the types recognised prenatally, and to find out if prenatal diagnosis can influence the incidence of urinary tract malformations detected after urinary tract infection in infancy.

\section{Patients and methods}

During a 48 month period from January 1983 to December 1986, 140 infants all of whom had what was thought to be their first urinary tract infection were admitted to the department of paediatrics. Urine was collected by bladder catheterisation or suprapubic aspiration, and all patients had bacterial counts of $10^{5} \times 10^{6} / 1$ or more. Most patients had a white cell count of more than $20 \times 10^{6} / 1$. Ultrasonography, voiding cystourethrography, and intravenous pyelography were performed in 110 infants. Ultrasonography was the only investigation in 30 patients. Urinary tract malformations were diagnosed prenatally in 39 infants after investigation of the fetal urinary tracts in 17500 pregnancies. The total number of pregnancies leading to live birth was about 34000 in our region during the study period. The findings are summarised in the table. Statistical analyses were done by the $\chi^{2}$ test and Student's $t$ test for unpaired data.

\section{Results}

The median (range) age of the 140 infants was 3 (4 days to 12 months) at the time of diagnosis. 
Thirty eight infants $(27 \%)$ presented during the first month of life and $80(57 \%)$ during the first 3 months. Only 23 infants $(16 \%)$ had their first urinary tract infections after they were 6 months old. The median (range) age of the 77 boys was 2 (4 days to 10 months) months. They were significantly younger than 63 girls with a median age of 5 ( 5 days to 12 months) months $(\mathrm{p}<0 \cdot 01)$. During the first three months boys had $69 \%$ of all urinary tract infections. Later on there was a female predominance, girls having $63 \%$ of all urinary tract infections $(\mathrm{p}<0.001)$. The male:female ratio was $2 \cdot 2: 1$ during the first three months and 1:1.7 thereafter; it was 1.2:1 during infancy (figure). Urinary tract malformations were present in 46 infants $(42 \%)$. There were no significant differences in age or sex among

Table Urinary tract malformations detected after first urinary tract infection in infancy and by prenatal diagnosis

\begin{tabular}{lcc}
\hline Diagnosis & $\begin{array}{l}\text { Urinary tract } \\
\text { infection }\end{array}$ & $\begin{array}{l}\text { Prenatal } \\
\text { diagnosis }\end{array}$ \\
\hline $\begin{array}{l}\text { Obstructive uropathy: } \\
\quad \text { Ureteropelvic obstruction }\end{array}$ & 8 & 18 \\
$\quad \begin{array}{l}\text { Primary obstructive } \\
\quad \text { megaureter }\end{array}$ & 3 & 7 \\
$\quad$ Duplication with megaureter & 2 & 1 \\
$\quad$ or ureterocoele & 4 & 1 \\
$\quad$ Posterior urethral valve & 1 & 0 \\
Horseshoe kidney & 1 & 8 \\
Multicystic dysplastic kidney & 27 & 4 \\
Vesicoureteral reflux & 46 & 39 \\
\hline Total & & \\
\hline
\end{tabular}

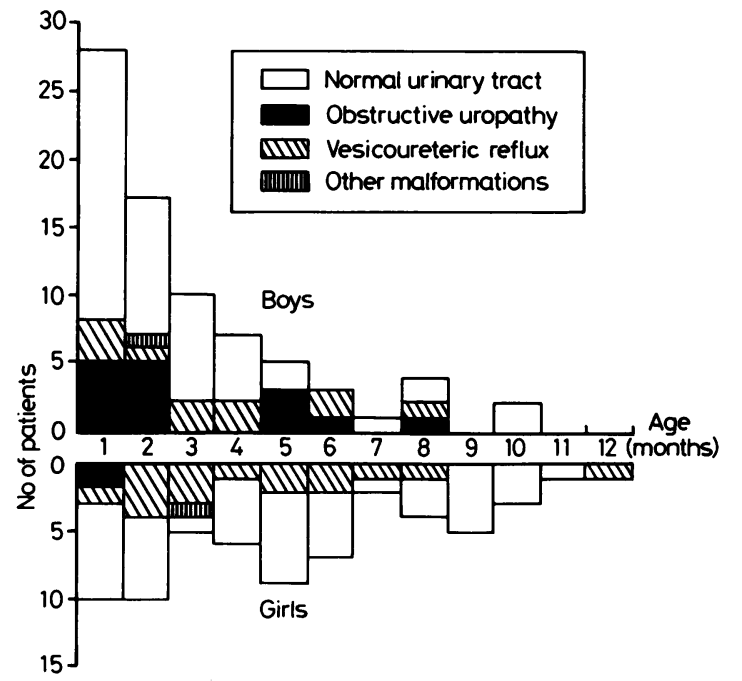

Figure Age and sex of 140 infants with urinary tract infections. infants with or without malformations. Of the infants with malformations $61 \%$ had urinary tract infections before they were 3 months old. The case fatality rate was $44 \%$ in this period, but this was not statistically different from the rate of $38 \%$ thereafter. Vesicoureteric reflux accounted for $59 \%$ of all malformations and obstructive uropathy for $37 \%$. During the first two months 12 of $17(70 \%)$ of all obstructive uropathies were diagnosed. In contrast $66 \%$ of all patients with vesicoureteric reflux had their urinary tract infection after they were 2 months old $(p<0 \cdot 05)$. Urinary tract obstructions were significantly more common in boys $(p<0.01)$. Vesicoureteric reflux, however, was more common in girls but not significantly so. The incidence of obstructive uropathy was $12 \%$ and of vesicoureteric reflux $25 \%$.

Forty six per cent of all malformations were diagnosed prenatally. Obstructive lesions and multicystic dysplastic malformations of the kidneys accounted for $90 \%$ of all prenatally diagnosed malformations. Of the obstructive malformations 27 of $44(61 \%)$ and eight of nine $(89 \%)$ of the multicystic dysplastic kidneys were diagnosed prenatally. In contrast, 27 of $31(87 \%)$ of refluxes were diagnosed after what was thought to be the first urinary tract infection.

\section{Discussion}

Fifty seven per cent of all urinary tract infections and $61 \%$ of all urinary tract malformations were diagnosed during the first 3 months of life; these data show the importance of this early period. Later on the incidence of urinary tract infection declined rapidly, but malformations were diagnosed at about the same rate. Malformations encourage infections and therefore contribute to the early development of urinary tract infections. In our patients malformations were not responsible for age and sex related differences. Other factors, therefore, such as the high incidence of haematogenous infections in the first few months of life ${ }^{10-12}$ and individual factors such as increased periurethral bacterial colonisation or even the lack of full development of the host defence mechanisms ${ }^{13}$ may be responsible. Boys were significantly younger than girls but there is no clear explanation for this. Other studies of urinary tract infection report a female predominance in childhood in contrast to the male predominance in infancy, ${ }^{134}$ but in our series the change in sex predominance took place during the fourth month of life.

Only a few previous studies contain detailed information about malformations diagnosed during infancy, and these report incidences of between 
$13 \%$ and $49 \% .{ }^{1368}$ Our data are within this range, but show a relatively high incidence of obstructive uropathy. Patient selection could be the reason, but the incidence of vesicoureteric reflux indicates that other factors-for example, a high awareness of urinary tract infection, the improved initial evaluation by ultrasonography, and perhaps other local factors-were responsible. We can confirm that urinary tract malformations, especially obstructive uropathies, are more common in boys. ${ }^{1-3} 14 \mathrm{Ob}-$ structive lesions were diagnosed earlier than vesicoureteric reflux. Obstructions are severe congenital malformations and seem to cause more early urinary tract infections than vesicoureteric reflux. In addition, only one part of vesicoureteric reflux is congenital, the other parts being secondary to urinary tract infections.

We know of no study that compared urinary tract malformations diagnosed prenatally with malformations diagnosed after urinary tract infections in infancy. Obstructive uropathies $(\mathrm{p}<0.01)$ and multicystic dysplastic kidneys $(p<0.05)$ were diagnosed more often prenatally. In contrast, most of the cases of vesicoureteric reflux were diagnosed after the first urinary tract infection $(p<0 \cdot 001)$. One would expect that the number of malformations especially obstructive lesions and multicystic dysplastic kidneys diagnosed after urinary tract infection in infancy would be reduced by an increase in prenatal diagnosis. Certainly this is true if thorough investigations are performed in all pregnancies. In our region thorough investigation of the fetal urinary tract was performed in just over half of all pregnancies, but though $46 \%$ of all urinary tract malformations were diagnosed prenatally, this did not influence the high incidence of malformations diagnosed after urinary tract infection in infancy. Even in our patients who had been investigated prenatally we diagnosed two malformations that were potentially recognisable on prenatal examination, namely ureteropelvic obstruction in one infant and a multicystic dysplastic kidney in another. Both were recognised after urinary tract infections in infancy. In general, we found an incidence of $0.2 \%$ of prenatal recognisable and primarily not lethal urinary tract malformations.
Our results show that further improvement in prenatal evaluation should be achieved, but even prenatal evaluation in all pregnancies will probably not significantly reduce the number of cases of vesicoureteric reflux detected after urinary tract infection. Thorough investigation by ultrasonography and voiding cystourethrography must be recommended in all infants who have urinary tract infections.

\section{References}

1 Bahna SL, Torp KH. The sex variable in childhood urinary tract infection. Acta Paediatr Scand 1975;64:581-6.

2 Bergström T. Sex differences in childhood urinary tract infection. Arch Dis Child 1972;47:227-32.

3 Winberg J, Andersen HJ, Bergström T, Jacobsson B, Larson H, Lincoln K. Epidemiology of symptomatic urinary tract infection in childhood. Acta Paediatr Scand 1974;252(suppl):1-20.

4 Birmingham Reflux Study Group. A prospective trial of operative versus non-operative treatment of severe vesicoureteric reflux: two years observation in 96 children. In: Hodson CJ, Heptinstall RH, Winberg J, eds. Contributions to nephrology: reflux nephropathy update 1983. Basle: Karger, 1984:169-85.

5 McKerrow W, Davidson-Lamb N, Jones PF. Urinary tract infection in children. Br Med J 1984;289:299-303.

6 Bourchier D, Abbott GD, Maling TMJ. Radiological abnormalities in infants with urinary tract infections. Arch Dis Child 1984;59:620-4.

7 Ginsburg CM, McCracken GH Jr. Urinary tract infections in young infants. Pediatrics 1982;69:409-12.

* Siegel SR, Sokoloff B, Siegel B. Asymptomatic urinary tract infection in infancy. Am J Dis Child 1973;125:45-7.

${ }^{9}$ Wettergren B, Jodal U, Jonasson G. Epidemiology of bacteriuria during the first year of life. Acta Paediatr Scand 1985;74: 925-33.

10 Smallpiece V. Urinary infection in the two sexes: Problems of aetiology. Lancet 1966;ii:1019.

11 Littlewood JM. 66 infants with urinary tract infection in the first month of life. Arch Dis Child 1972;47:218-26.

12 Bergström T, Larson H, Lincoln K, Winberg J. Studies of urinary tract infections in infancy and childhood XII. Eighty consecutive patients with neonatal infection. J Pediatr 1972;80: 858-66.

13 Mannhardt W, Schofer O, Schulte-Wissermann H. Pathogenic factors in recurrent urinary tract infections and renal scar formation in children. Eur J Pediatr 1986;145:330-6.

14 Saxena SR, Laurance BM, Shaw DG. The justification for early radiological investigations of urinary-tract infection in children Lancet 1975;i:403-4.

Correspondence to Dr E Ring, University Kinderklinik Graz, Auenbruggerplatz, A-8036 Graz, Austria.

Accepted 27 November 1987 